\title{
The Evolution of Perforator Flap Breast Reconstruction: Twenty Years after the First DIEP Flap
}

\author{
Claragh Healy, FRCS(Plast), PhD ${ }^{1}$ Robert J. Allen Sr., MD²
}

${ }^{1}$ St. Andrew's Centre for Burns and Plastics, Broomfield Hospital, Chelmsford, United Kingdom

2 Department of Plastic Surgery, New York University Langone Medical

Address for correspondence Claragh Healy, FRCS (Plast), PhD, St. Andrew's Centre for Burns and Plastics, Broomfield Hospital, Centre, New York and Louisiana Health Sciences Centre, Louisiana

\begin{abstract}
Keywords

- breast reconstruction

- microsurgery

- flap

It is over 20 years since the inaugural deep inferior epigastric perforator (DIEP) flap breast reconstruction. We review the type of flap utilized and indications in 2,850 microvascular breast reconstruction over the subsequent 20 years in the senior author's practice (Robert J. Allen). Data were extracted from a personal logbook of all microsurgical free flap breast reconstructions performed between August 1992 and August 2012. Indication for surgery; mastectomy pattern in primary reconstruction; flap type, whether unilateral or bilateral; recipient vessels; and adjunctive procedures were recorded. The DIEP was the most commonly performed flap (66\%), followed by the superior gluteal artery perforator flap (12\%), superficial inferior epigastric artery perforator flap (9\%), inferior gluteal artery perforator flap (6\%), profunda artery perforator flap (3\%), and transverse upper gracilis flap (3\%). Primary reconstruction accounted for 1,430 flaps (50\%), secondary 992 (35\%), and tertiary 425 (15\%). As simultaneous bilateral reconstructions, $59 \%$ flaps were performed. With each flap, there typically ensues a period of enthusiasm which translated into surge in flap numbers. However, each flap has its own nuances and characteristics that influence patient and physician choice. Of note, each newly introduced flap, either buttock or thigh, results in a sharp decline in its predecessor. In this practice, the DIEP flap has remained the first choice in autologous breast reconstruction.
\end{abstract}

To date, the senior author (Robert J. Allen) has performed more than 3,500 microsurgical flap surgeries; more than 2,850 have been microsurgical breast reconstructions. The deep inferior epigastric perforator (DIEP) flap, superficial inferior epigastric artery (SIEA), gluteal artery perforator (GAP) flaps, transverse upper gracilis (TUG) flap, and most recently the profunda artery perforator (PAP) flap have been utilized to varying degrees in this practice. Over 20 years of experience in autologous microvascular breast reconstruction have been influenced by changes in breast cancer treatment, vascular imaging, patient empowerment, and globalization of health care. Here, we examine the trends in flap choice that have emerged during the 20 years since performing the inaugural DIEP flap in a microvascular breast reconstruction practice. ${ }^{1}$

\section{Materials and Methods}

Data were extracted from a personal logbook of all microsurgical free flaps from August 1992 to August 2012, and divided into 12 monthly segments to facilitate a 20 -year comparison. Information recorded included date of surgery, location, referral source, and indication for surgery and mastectomy pattern in primary received

June 14, 2013

accepted after revision

August 12, 2013

published online

October 25, 2013
Copyright $\odot 2014$ by Thieme Medical Publishers, Inc., 333 Seventh Avenue, New York, NY 10001, USA. Tel: +1(212) 584-4662.
DOI http://dx.doi.org/ 10.1055/s-0033-1357272. ISSN 0743-684X. 


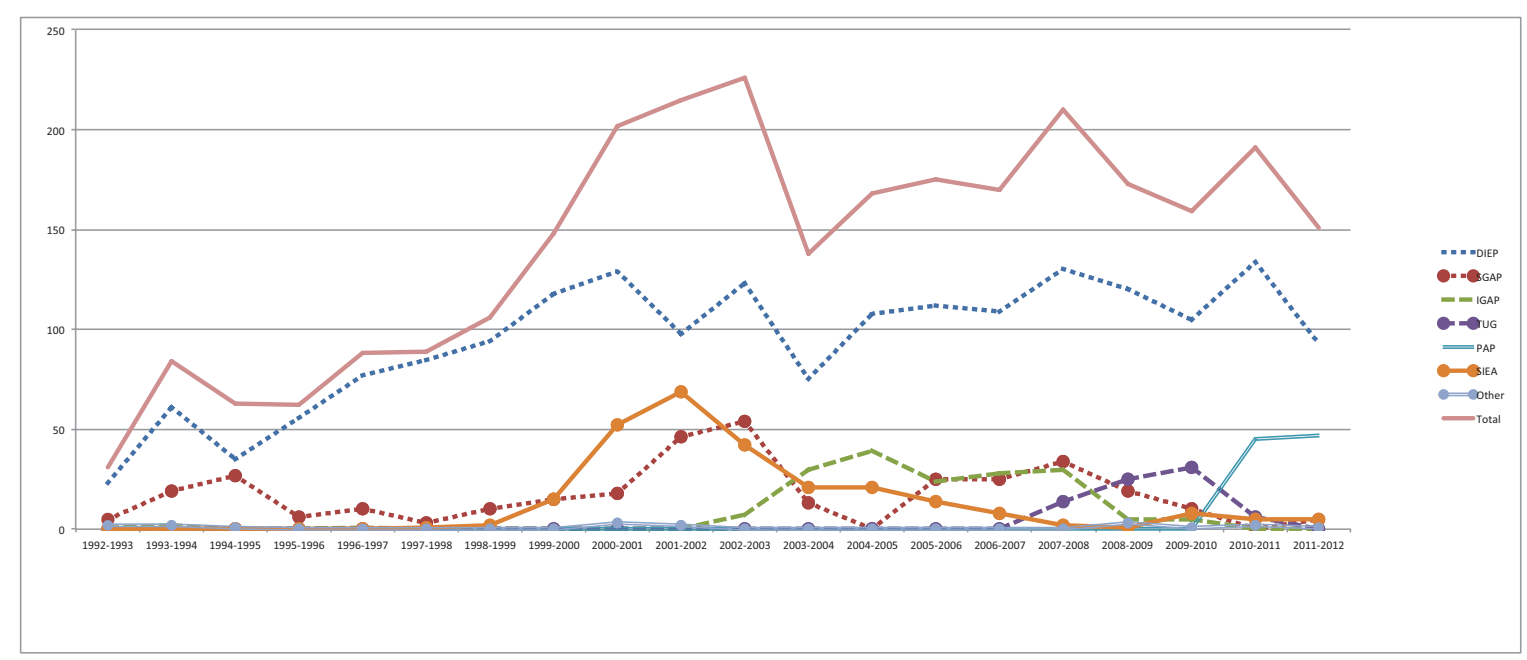

Fig. 1 Trends in overall flaps performed.

reconstruction. Indication for flaps was recorded as primary, at the time of mastectomy; secondary, at a time separate from mastectomy; and tertiary, with a history of previous reconstruction. Flap type, whether unilateral or bilateral; recipient vessels; and adjunctive procedures were also recorded.

\section{Results}

Between August 1992 and August 2012, 2,850 flaps were performed for breast reconstruction. The median volume of flaps performed per year was 155 (mean 142). The maximum number of flaps performed per year was 226 in 2002 to 2003. A relative decrease in the number of flaps performed over 12 months was noted in 2003 to 2004 (-Fig. 1).

The DIEP was the most commonly performed flap, followed by the superior gluteal artery perforator (SGAP), SIEA, inferior gluteal artery perforator (IGAP), PAP, and TUG, and less than $1 \%$ were other flap types (-Table 1). Primary reconstruction accounted for 1,430 (50\%), secondary 992 (35\%), and tertiary 425 (15\%). The dates of the index proce-

Table 1 Cumulative flap types

\begin{tabular}{|l|l|}
\hline Flap type & Total no. (\%) \\
\hline DIEP & $1,885(66 \%)$ \\
\hline SGAP & $344(12 \%)$ \\
\hline SIEA & $266(9 \%)$ \\
\hline IGAP & $172(6 \%)$ \\
\hline PAP & $92(3 \%)$ \\
\hline TUG & $76(3 \%)$ \\
\hline Other & $17(<1 \%)$ \\
\hline Total & 2,850 \\
\hline
\end{tabular}

Abbreviations: DIEP, deep inferior epigastric perforator; IGAP, inferior gluteal artery perforator; SGAP, superior gluteal artery perforator; SIEA, superficial inferior epigastric artery; PAP, profunda artery perforator; TUG, transverse upper gracilis flap. dure demonstrate a variable time lag between performing the first unilateral and first bilateral; the IGAP accounts for the longest period, whereas the first TUG was a bilateral procedure (-Table 2 ).

The DIEP flap was the most frequently performed flap each year (-Fig. 1). In 2001 to 2002, the SIEA flaps peaked in number, with a concomitant decline in the number of DIEP flaps. Since then the use of the SIEA declined until 2008 to

Table 2 Date of index procedure

\begin{tabular}{|l|l|l|}
\hline Flap type & Procedure & Date \\
\hline \multirow{4}{*}{ DIEP } & Unilateral & August 3, 1992 \\
\cline { 2 - 3 } & Simultaneous bilateral & December 8, 1993 \\
\cline { 2 - 3 } & Peak year (number) & 2010-2011 (134) \\
\hline \multirow{5}{*}{ SGAP } & Unilateral & February 15, 1993 \\
\cline { 2 - 3 } & Simultaneous bilateral & August 25, 1994 \\
\cline { 2 - 3 } & Peak year (number) & 2002-2003 (54) \\
\hline \multirow{5}{*}{ SIEA } & Unilateral & March 29, 1993 \\
\cline { 2 - 3 } & Simultaneous bilateral & January 4, 2005 \\
\cline { 2 - 3 } & Peak year (number) & 2004-2005 (39) \\
\cline { 2 - 3 } & Unilateral & June 10, 1989 \\
\cline { 2 - 3 } & Simultaneous bilateral & March 14, 2000 \\
\cline { 2 - 3 } & Peak year (number) & 2001-2002 (69) \\
\hline TUG & Unilateral & October 15, 2007 \\
\cline { 2 - 3 } & Simultaneous bilateral & October 15, 2007 \\
\cline { 2 - 3 } & Peak year (number) & 2009-2010 (31) \\
\hline PAP & Unilateral & October 28, 2010 \\
\cline { 2 - 3 } & Simultaneous bilateral & November 30, 2010 \\
\cline { 2 - 3 } & Peak year (number) & 2011-2012 (47) \\
\hline \multirow{5}{*}{} & &
\end{tabular}

Abbreviations: DIEP, deep inferior epigastric perforator; IGAP, inferior gluteal artery perforator; SGAP, superior gluteal artery perforator; SIEA, superficial inferior epigastric artery; PAP, profunda artery perforator; TUG, transverse upper gracilis flap. 


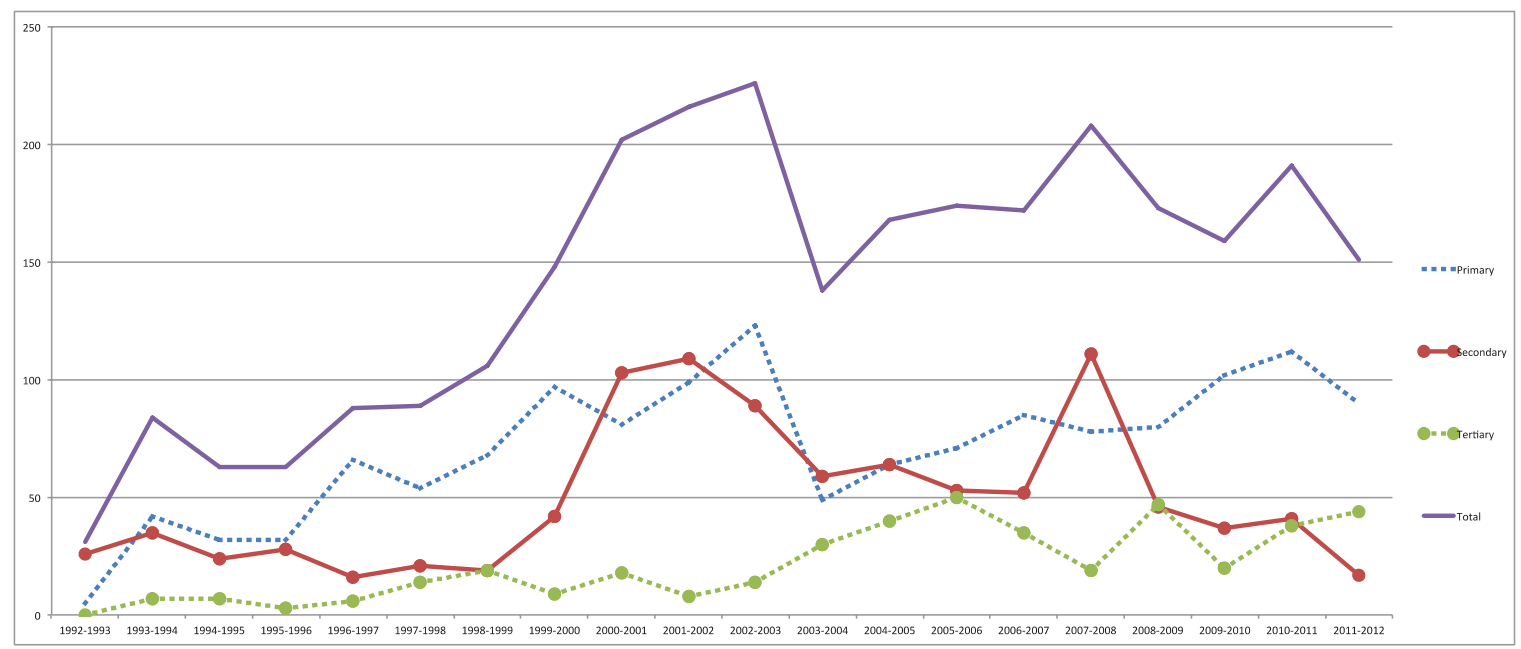

Fig. 2 Trends in indication for flap.

2009 when routine preoperative imaging reliably identified the suitability of the SIEA pedicle for flap harvest. The number of SGAP flaps, first performed in 1993, peaked in 2002 to 2003. Subsequent to this peak, the number of nonabdominalbased flaps remained relatively constant.

The number of primary reconstructions was relatively constant in proportion to the total number of flaps; both mean and median are $50 \%$ of total reconstructions, ranging from 16 to $75 \%$ (-Fig. 2). The number of secondary flaps initially accounted for the greatest number of reconstructions in 1992 to 1993 (84\%) and most recently, 2011 to 2012, the least $(11 \%)$. Overall, the median number of secondary flaps was 34\% (mean 36\%). Tertiary reconstructions have accounted for $15 \%$ of all reconstructions. The proportion of tertiary flaps gradually increased over the study period, in 2011 to 2012 accounting for $44 \%$ of reconstructions.

Of the 2,850 flaps, 1,692 (59\%) (846 patients) were performed as simultaneous bilateral reconstruction. Again the DIEP flap was the most commonly performed bilateral procedure (64\%) (-Table 3 ). There was a general trend in the

Table 3 Total number of simultaneous procedures

\begin{tabular}{|l|l|}
\hline Bilateral flaps & Total no. patients (flaps) \\
\hline DIEP & $539(1,078)$ \\
\hline Mixed & $87(174)$ \\
\hline SGAP & $71(142)$ \\
\hline IGAP & $39(78)$ \\
\hline SIEA & $39(78)$ \\
\hline PAP & $38(76)$ \\
\hline TUG & $30(60)$ \\
\hline Other & $3(6)$ \\
\hline
\end{tabular}

Abbreviations: DIEP, deep inferior epigastric perforator; IGAP, inferior gluteal artery perforator; SGAP, superior gluteal artery perforator; SIEA, superficial inferior epigastric artery; PAP, profunda artery perforator; TUG, transverse upper gracilis flap. overall number of bilateral flaps over the study period. Between 1999 and 2000, there was a 50\% increase in the number of bilateral flaps (-Fig. $\mathbf{3}$ ).

The first nipple-sparing mastectomy (NSM) was performed in January 1999; however, it was not until 2005 to 2006 that it became a consistently performed procedure (-Fig. 4). Most recently, $87 \%$ of primary reconstructions were NSM.

\section{Discussion}

Breast reconstruction is a key element to the successful treatment of breast cancer and has become the standard of care in the western world. Autologous microvascular breast reconstruction is recognized as the gold standard for reconstructive options, affording the patient a natural, enduring breast that can integrate with ease into their body image. The senior author has pioneered many of the current perforator flap choices. ${ }^{1-4}$ Incorporating a flap into practice and its subsequent longevity is determined by factors including reliable vasculature, an acceptable donor site to patient and surgeon, reproducibility and efficiency with which the procedure may be performed, and complication rates. ${ }^{1-5}$ In addition to intrinsic flap features, extrinsic forces such as preoperative imaging and mastectomy patterns have helped mold current practice.

The DIEP flap is clearly the first choice for both bilateral and unilateral procedures. However, several alternatives have been explored. Enthusiasm for the SIEA flap, largely due to minimal donor site morbidity, peaked in 2002, which corresponded with a decline in the number of DIEP flaps. The primary limitation with the SIEA is the reliability of the vascular pedicle. Studies have variably reported the presence of vessels of sufficient caliber in 24 to $70 \%$. $^{6,7}$ The current use of preoperative imaging has promoted the use of the SIEA flap in selected cases where the vascular anatomy is compatible with free tissue transfer. However, the overall number of SIEA flaps remains low. 


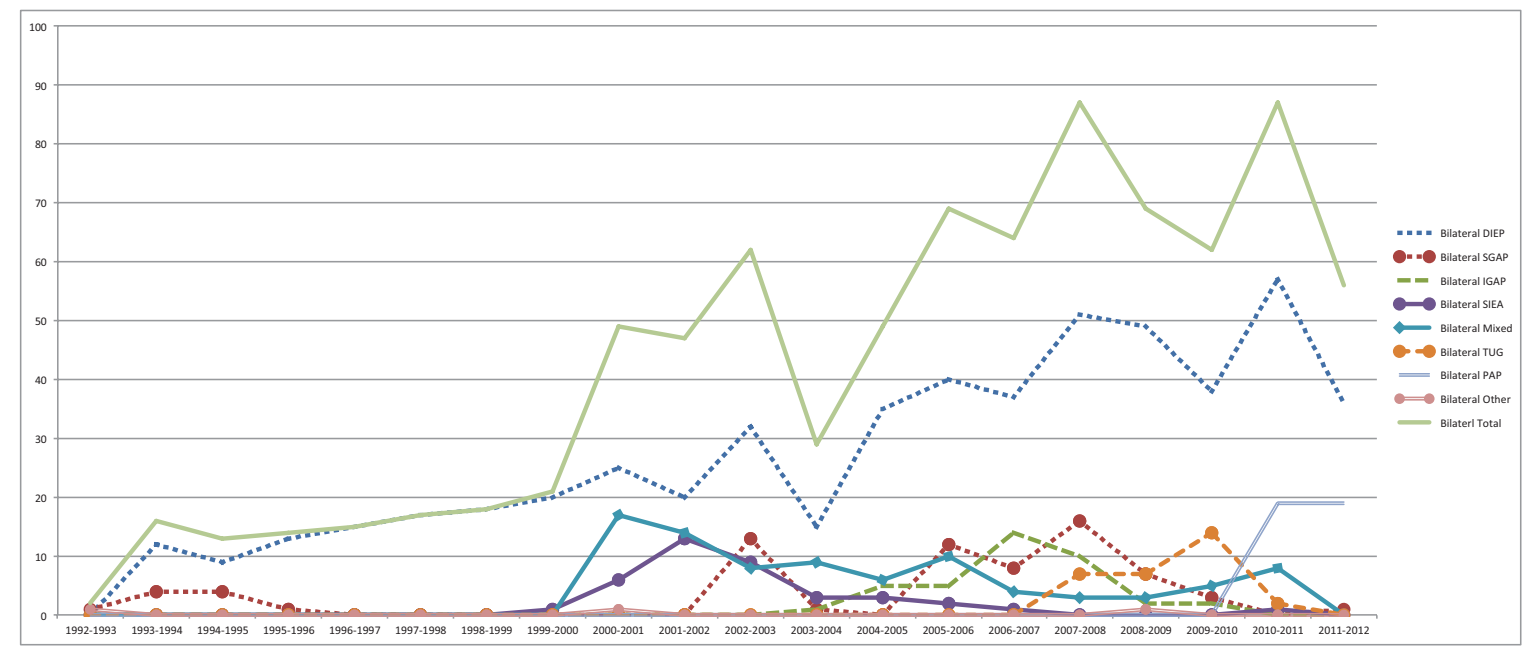

Fig. 3 Trends in simultaneous bilateral procedures.

When the abdomen is not utilized as a donor for autologous reconstruction, the second flap of choice has varied between the various buttock/thigh flaps. There is a notable trend that each buttock/thigh-based flap results in a sharp decline in its predecessor starting with the SGAP, then IGAP, TUG, and most recently the PAP flap. The introduction of the PAP flap corresponded with a complete cessation in IGAP and TUG flaps; however, the SGAP was still occasionally used. The septocutaneous SGAP and the crease IGAP both were described to address the perceived issues with the GAP flaps, the dissection, and donor site aesthetics. ${ }^{3,8}$ Despite this, donor site concern is a significant problem within the patient population and from a surgical perspective, bilateral GAP reconstructions can be time-consuming. The TUG flap, first introduced to the practice in October 2007, was a relatively simple and efficient flap harvest. However, the donor site scar, wound-related issues, the potential for lymphedema, and the harvesting of muscle promoted the search for an alternative. The septocutaneous TUG, deep femoral artery perforator, and superficial femoral artery perforator) flaps were all predecessors of the PAP flap., ${ }^{4,9}$ The PAP flap is currently the second flap of choice, and the series to date of
92 patients is encouraging; however, whether it will have the longevity of the DIEP is unclear.

The indications for reconstruction have changed slowly over the 20 years. Secondary reconstructions predominated in the very early years, but soon were overtaken by primary reconstruction. There are two notable increases in secondary reconstruction, in 1999 to 2000 and 2006 to 2007. Potential contributing factors include The Women's Health and Cancer Rights Act (WHCRA) which became federal law on January 1, 1999. This legislation mandated health care payer coverage for postmastectomy breast reconstruction; however, state law in many areas had similar legislation before this, and despite passage of this legislation, breast reconstruction rates in the United States remain low. ${ }^{10}$ Another possible explanation for the increase in secondary reconstructions was the launch of the inaugural DIEP Web site in 1998, with the first recorded Web site referral sourced flap was performed in August 1998. The globalization of health care, as described by Thomas Friedman, has helped to raise the profile of autologous breast reconstruction, with patient enquiries from an international source. ${ }^{11}$ In addition, there was considerable media attention surrounding the first unilateral DIEP

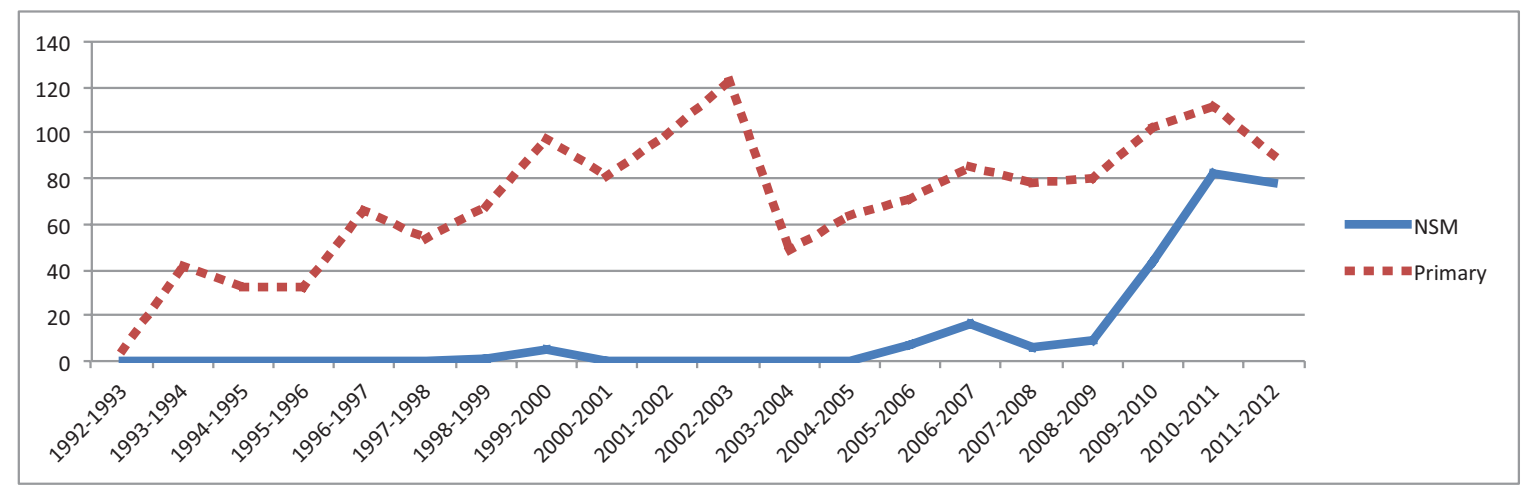

Fig. 4 Total number of primary reconstructions and number of NSM. 
transplant in 2000 and the first bilateral DIEP transplant performed in 2006 resulted in a peer-reviewed publication. ${ }^{12}$

Tertiary reconstruction numbers have steadily increased during the study period, overall accounting for $15 \%$ of flaps, but $44 \%$ of past years flaps. ${ }^{13}$ The majority are patients who have had implant-based reconstructions. Although not reflected in this practice, American Society of Plastic Surgeons (ASPS) statistics indicate that greater than $80 \%$ of all breast reconstructive procedures are implant based. Given the recognized limitations and longevity of implant-based reconstruction, it is reasonable to predict that the trend toward increasing tertiary flap reconstruction would continue.

Simultaneous bilateral reconstructions account for $59 \%$ of flaps performed and have generally trended toward an increase over the 20 years. A trend toward increased contralateral prophylactic mastectomy (CPM) has been noted in the United States, in contrast with Europe, a phenomenon described as a minimal or maximal approach to breast cancer. ${ }^{14}$ A recent European study demonstrated a stable rate of 2.6\% CPM and suggested that different medicosocial and cultural contexts between the United States and Europe may account for the differing trends in CPM. ${ }^{15}$

Mastectomy patterns have also evolved during the study period. The first NSM was performed relatively early when considering national and international practice; however, this was facilitated by a close working relationship with Dr. Alan Stolier, one of the pioneers in this arena. ${ }^{16}$ Recent data indicate that NSM accounts for $87 \%$ of primary reconstruction in this practice; these figures also reflect the number of bilateral procedures.

Intrinsic and extrinsic factors have helped shape over 20 years of practice devoted primarily to microvascular breast reconstruction. With the introduction of each new flap, there typically ensued a period of enthusiasm which translated into surge in flap numbers. There is a notable trend that each buttock/thigh-based flap has resulted in a sharp decline in its predecessor. What is apparent from this practice is that the DIEP flap has remained the first choice in autologous breast reconstruction.

\section{Acknowledgments}

Dr. Healy would like to thank the Royal College of Surgeons in Ireland (RCSI) for supporting her fellowship with Dr. Allen, through the Gussie Mehigan Scholarship Travel Grant and RCSI Ethicon Travel Grant.

\section{References}

1 Allen RJ, Treece P. Deep inferior epigastric perforator flap for breast reconstruction. Ann Plast Surg 1994;32(1):32-38

2 Allen RJ, Tucker C Jr. Superior gluteal artery perforator free flap for breast reconstruction. Plast Reconstr Surg 1995;95(7):12071212

3 Allen RJ, Levine JL, Granzow JW. The in-the-crease inferior gluteal artery perforator flap for breast reconstruction. Plast Reconstr Surg 2006;118(2):333-339

4 Allen RJ, Haddock NT, Ahn CY, Sadeghi A. Breast reconstruction with the profunda artery perforator flap. Plast Reconstr Surg 2012; 129(1):16e-23e

5 Gill PS, Hunt JP, Guerra AB, et al. A 10-year retrospective review of 758 DIEP flaps for breast reconstruction. Plast Reconstr Surg 2004; 113(4):1153-1160

6 Spiegel AJ, Khan FN. An Intraoperative algorithm for use of the SIEA flap for breast reconstruction. Plast Reconstr Surg 2007;120(6): 1450-1459

7 Rozen WM, Chubb D, Grinsell D, Ashton MW. The variability of the Superficial Inferior Epigastric Artery (SIEA) and its angiosome: A clinical anatomical study. Microsurgery 2010;30(5): 386-391

8 Tuinder S, Chen CM, Massey MF, Allen RJ Sr, Van der Huist R. Introducing the septocutaneous gluteal artery perforator flap: a simplified approach to microsurgical breast reconstruction. Plast Reconstr Surg 2011;127(2):489-495

9 Schneider LF, Vasile JV, Levine JL, Allen RJ. Deep femoral artery perforator flap: a new perforator flap for breast reconstruction. J Reconstr Microsurg 2011;27(9):531-536

10 Wilkins EG, Alderman AK. Breast reconstruction practices in north America: current trends and future priorities. Semin Plast Surg 2004;18(2):149-155

11 Friedman TL. The World Is Flat: A Brief History of the TwentyFirst Century, 1st ed. New York: Farrar Straus and Giroux; 2005

12 Allen RJ Jr, LoTempio MM, Craigie JE, Allen RJ Sr. Transplantation in identical twins: another option for breast reconstruction. Plast Reconstr Surg 2008;122(4):1019-1023

13 Levine SM, Lester ME, Fontenot B, Allen RJ Sr. Perforator flap breast reconstruction after unsatisfactory implant reconstruction. Ann Plast Surg 2011;66(5):513-517

14 Brewster AM, Parker PA. Current knowledge on contralateral prophylactic mastectomy among women with sporadic breast cancer. Oncologist 2011;16(7):935-941

15 Güth U, Myrick ME, Viehl CT, Weber WP, Lardi AM, Schmid SM. Increasing rates of contralateral prophylactic mastectomy - a trend made in USA? Eur J Surg Oncol 2012;38(4):296-301

16 Stolier AJ, Wang J. Terminal duct lobular units are scarce in the nipple: implications for prophylactic nipple-sparing mastectomy: terminal duct lobular units in the nipple. Ann Surg Oncol 2008; 15(2):438-442 